\title{
Incentives Matter, But What Do They Mean? Understanding the Meaning of Market Coordination
}

\author{
Erwin Dekker, Blaž Remic \& Carolina Dalla Chiesa
}

To cite this article: Erwin Dekker, Blaž Remic \& Carolina Dalla Chiesa (2019): Incentives Matter, But What Do They Mean? Understanding the Meaning of Market Coordination, Review of Political Economy, DOI: 10.1080/09538259.2019.1628341

To link to this article: https://doi.org/10.1080/09538259.2019.1628341
(2) 2019 The Author(s). Published by Informa UK Limited, trading as Taylor \& Francis Group
曲 Published online: 09 Sep 2019.

Submit your article to this journal

Q View related articles $\sqsubset$

View Crossmark data $\nearrow$ 


\title{
Incentives Matter, But What Do They Mean? Understanding the Meaning of Market Coordination
}

\author{
Erwin Dekker, Blaž Remic and Carolina Dalla Chiesa \\ Erasmus School of History, Culture \& Communication, Rotterdam, Netherlands
}

\begin{abstract}
This article argues that the discussion of incentives in economics neglects a crucial question: why are some incentives felt as powerful reasons to alter actions, while other incentives have little, or even counterproductive, effect? We argue that an answer to this question can be found in recent empirical work in economic sociology, institutional economics and Austrian economics. This work studies the meaning of incentives in particular social settings and shows that incentives become meaningful in relation to those settings. We demonstrate that it illuminates why certain incentives are perceived as powerful reasons for action, while others are mostly ignored. We also explain why incentives are typically tied to certain social roles that can be identified through ideal-type analysis, and why situations of high uncertainty are of particular use for studying the activity of actors. In order to understand entrepreneurial action, financial markets, and why monetary rewards and market exchange are sometimes perceived as the wrong type of incentive, research should focus on how an uncertain future is understood by actors. We identify four building blocks in the work of Alfred Schutz, and suggest they yield a constructive research program at the intersection between economics and sociology.
\end{abstract}

\section{ARTICLE HISTORY}

Received 22 October 2018

Accepted 16 May 2019

\section{KEYWORDS}

Incentives; coordination;

Schutz; economic sociology

JEL Classifications

D01; D02; D91; B40; B53; Z13

\section{Introduction}

The idea that incentives matter has become a near mantra in economics. However, there is something peculiar about the idea that incentives matter, an oddity that gets little attention in the discipline. Why are some incentives felt as very powerful reasons to alter actions at the same time that other incentives hardly manage to produce any effect at all and yet other incentives actually have counterproductive effects? Why do social norms sometimes act as a strong incentive not to cheat, while in other situations social norms seem powerless to prevent cheating? And why are monetary incentives often a powerful stimulus for a certain type of behavior, yet at other times they actually work as a deterrent? This paper argues that the start of an answer to these questions is present in current literature at the intersection of sociology and economics.

CONTACT Erwin Dekker e.dekker@eshcc.eur.nl E Erasmus School of History, Culture \& Communication, P.O. Box 1738, 3000 DR Rotterdam, Netherlands

(c) 2019 The Author(s). Published by Informa UK Limited, trading as Taylor \& Francis Group

This is an Open Access article distributed under the terms of the Creative Commons Attribution-NonCommercial-NoDerivatives License (http://creativecommons.org/licenses/by-nc-nd/4.0/), which permits non-commercial re-use, distribution, and reproduction in any medium, provided the original work is properly cited, and is not altered, transformed, or built upon in any way. 
In this growing body of research, both economists and sociologists see the fundamental problem of the social sciences as the question of how coordination between individuals with different objectives and interests can come about. Rather than thinking in objective terms about incentives, they study how coordination comes about through processes of meaning-making. These studies analyze how social environments and embedded incentives come to be understood in particular ways. This work disputes the existence of 'hard' objective incentives, and instead see only incentives as understood by the actor. In empirical approaches within economics, particularly the institutional branch, and in pragmatic approaches to decision-making in sociology, we see a convergence not only in the type of problems studied and the empirical strategies pursued, but also in their underlying theoretical and methodological approach. It shows important similarities with the mid-twentiethcentury work of Alfred Schutz and his social phenomenology, and identifies various methodological strategies as embracing a common 'Schutzian' answer to the problem of mutual coordination. Lastly, we explain why this convergence is a fruitful ground for a shared approach to study economic interaction and human interaction more broadly.

The empirical approaches we are talking about comprise work in institutional and Austrian economics on the one hand and work in the tradition of pragmatic (economic) sociology on the other. In these approaches, coordination among individuals with subjective understandings of the situation is the central theoretical problem, and empirical work focuses on the emergence of intersubjective understandings through communication, signaling, conventions, institutions, and formal or informal rules. The flip side of that focus is how shared understandings break down, are upset, and change. Although this might sound highly abstract, there is an important difference between these approaches, on the one hand, and alternative approaches in economics and sociology. This difference is, first and foremost, that everyday understandings of the social world are taken as the starting point in these alternative approaches, something labeled as 'the pragmatic approach' in sociology (Thévenot 2001). This distinguishes them from more structuralist approaches in sociology, such as Marxist and social network analysis traditions, and the rational choice approach in economics, based on costs and constraints.

Based on this pragmatic methodology, studies often focus on everyday understandings of the social world. They are particularly attentive to the open-ended nature of human action, and the potential for coordination and discoordination in social interaction. Scholars involved in these traditions seek to study how intersubjective understandings coordinate individual and collective plans, and how particular (powerful) agents seek to change these understandings to their advantage. In contrast to structuralist perspectives, which emphasize the close-ended nature of, and the determinism in existing structures, the alternative approach pays close attention to interpersonal meaning structures that facilitate decision-making processes.

Nevertheless, we recognize there are differences between the individual authors within and between these approaches, and there remain important differences between the more sociologically and more economically minded authors. Most notably, they disagree over the extent to which individuals are able to shape intersubjective understandings, and the agency ascribed to these intersubjective structures. But such disagreements should not obscure the fundamental agreement and shared conception of the problem of coordination in human interaction, or the need to study coordination processes through the formation of shared understandings. 
This paper provides three contributions. First, it shows the nature of the convergence between recent work in economic sociology and economics. Second, it demonstrates that this convergence has one of its theoretical roots in the intersubjective social phenomenology of Alfred Schutz, whose influence tends to be unacknowledged. The work of Schutz will help clarify the distinctiveness of the recent convergence, and show how different elements of different alternative approaches might form a coherent research program. Third, this paper applies these insights to critique the way economists tend to think about incentives as objective stimuli for certain types of behavior. It demonstrates how the empirical work discussed provides an alternative way to think about incentives as intersubjectively understood reasons for performing a particular action. This will enrich the theory of incentives, which do not matter objectively, independent of their meaning, but matter precisely because they have meaning to actors.

The paper proceeds as follows. Section Two identifies four Schutzian 'building blocks' that allow us to detect shared elements in the different empirical approaches. This provides hints for a renewed theoretical and methodological justification of some recent empirical work. Section Three is devoted to a discussion of these approaches in sociology, and Section Four examines these approaches in economics. Section Five explains why this convergence is not merely an interesting opportunity for cross-disciplinary learning, but also an important correction to prevalent ideas in sociology and economics. In particular, it addresses what economists can learn from these alternative approaches for studying incentives.

\section{Four Schutzian Building Blocks}

Alfred Schutz was one of several thinkers who brought sociology and phenomenology together by combining the contributions of Max Weber and Edmund Husserl (Wagner 1983). For Schutz, the social world is a world of meaning in which individuals coordinate their actions with those of others. In order for this to be possible, individuals enact ways of understanding the world around them. What sets Schutz's approach apart from many other sociological approaches is that he embraces Husserl's phenomenology to discuss the problem of intersubjectivity in the realm of the social world. He unveils the everyday life structures through the notion of subjectively meaningful actions as his starting point. These experience-based understandings are the subject of his first book Der sinnhafte Aufbau der sozialen Welt. Our purpose here is not to give an overview of Schutz's intellectual project, which is covered by Wagner (1983) and Prendergast (1986), ${ }^{1}$ but rather to identify four central tenets in his work. ${ }^{2}$ The following sections identify similarities between elements of his work and recent empirical approaches in sociology and economics.

The first building block, and most central notion in his work, is that of Verstehen, which lies at the core of everyday understandings of the world. Schutz adopted this interpretive methodological position from his predecessors, especially Max Weber, but critically expanded on it. Verstehen, for him, is relevant on multiple levels. First, there is the

\footnotetext{
${ }^{1}$ These two authors disagree on the connection between Schutz and Austrian school of economics. Augier (1999) correctly observes that Wagner downplays the importance of this connection in Schutz's intellectual history.

${ }^{2}$ We draw primarily on the English translation of his seminal book (Schutz 1967) and the collection of essays published in Schutz (1962).
} 
problem for the actor in understanding the actions of others and drawing out his own plan or project. Schutz thinks of individuals as coordinating their own actions with the potential actions of others in mind because interpretations of the social world of individuals are subjective. Second, there is the problem for the outside observer, who is similarly engaged in a project of Verstehen in order to figure out what individuals have intended or meant with their action. This also brings up the epistemological problem of any social science project: how much can we ultimately know about the plans and motivations of others?

In order to deal with both the first and the second problem, Schutz argues we have a need for the Weberian notion of ideal types, which he expands by including the everyday life perspective and providing a way for a phenomenologically based research. This leads us to the second building block, a discussion of how actors make sense of the (potential) actions of others and the social world by drawing on ideal-types reasoning. This is particularly true when we move beyond the interaction of a very small number of individuals, which Schutz sought to do. Since actors cannot form subjective interpretations of each individual's action, they rely on types of actions, or ideal-typical motivation, of which the profit-oriented businessman is but one example. These ideal types are not fixed, but depend on the relevant action-situation of the actor. Correspondingly, the scientific observer faces a similar epistemological problem. If we are analyzing the real estate market we might want to differentiate between certain ideal-typical actors such as the financier, the real estate agent and the home-owner, while if we are analyzing the economy as a whole we might feel the need to form higher-order ideal types of a greater degree of anonymity to arrive at relatively concise explanations. ${ }^{3}$

The third Schutzian building block, perhaps the most important for the purpose of this paper, is how interpersonal coordination comes about. A central aspect of Schutz's theory of human action is the idea that individuals form plans or projects about their actions, and within these projects, they have to take into account what they expect others to do. This process of project formation ${ }^{4}$ is the coordinative and potentially disruptive process of social interaction. As is well known, coordination is a central concept in modern economics, in particular in game theory, but Schutz's primary concern is how shared understandings of particular situations come about because only when there exists a shared understanding of the situation are individuals likely to form correct expectations about the behavior of others. It is here that his emphasis on intersubjectivity and the way in which situations become socially constructed, or built-up, becomes central. In modern terms, one might say that institutions help foster shared understandings by providing what Lachmann (1971) has called 'guideposts' for the behavior of various individuals. But as we will see below, many empirical studies in economic sociology and economics have paid particular interest to situations involving great uncertainty, where coordination is anything but given.

From interaction among individuals emerges a pattern of coordination. Schutz calls these patterns 'domains of relevance' or 'distinct provinces of meaning', which is the fourth building block. ${ }^{5}$ For Schutz, the social world is not a coherent whole, but instead

\footnotetext{
${ }^{3}$ Machlup (1936) applied the Schutzian distinction between different degrees of anonymity of ideal types to the study of economic activity, showing that problems involving different ideal types must also involve different methodological approaches.

${ }^{4}$ Schutz's work on project formation and emphasis on time originates in the work of Henri Bergson.

${ }^{5}$ In developing this concept Schutz draws on William James who analyzed reality as consisting of several sub-universes, 'each with its own special and separate style of existence' (James 1890, p. 291).
} 
a set of somewhat autonomous orders that overlap in complex ways. The provinces of meaning create what in modern sociology is called 'spheres or logics of interaction', which are internally coherent, but might conflict with other spheres or logics (Thornton, Ocasio, and Lounsbury 2012; Boltanski and Thévenot 2006). The strong point of Schutz is that he explicitly distances himself from the idea that these provinces are somehow ontologically different. Instead, the boundaries between them come about through the meaning-making process of human interaction, and hence new situations can be conflictual in part because it is not clear how they should be classified by the actors.

These four building blocks are, perhaps surprisingly, present in important strands of the contemporary empirical literature in economics and (economic) sociology. Sometimes Schutz's legacy is implicitly acknowledged, while in other instances his themes have been rediscovered quite independently from his work. His work, however, provides a good framework for interpreting the convergence between economics and sociology. This is not a paper in the history of ideas, so we are not primarily concerned with how these contemporary authors came to adopt their approach; instead, we demonstrate how they converge around these four building blocks.

\section{Recent Economic Sociology}

A prominent description of economic sociology is that the field seeks to combine into a unified analysis economic interests and social relations (Swedberg 2003). This is done in structuralist ways, where little attention is paid to meaning-making and more to underlying social and economic differences, and it is done in less structuralist ways, where attention is directed to actor-perspectives and processes of meaning-making (in the extreme by such approaches as ethnomethodology, which relies completely on qualitative actor-perspectives). It is important to observe that Schutz cannot simply be placed within one camp. Although his work utilizes the methodology of Verstehen, the goal is to explain social coordination and social structures.

Within economic sociology, the approach of Viviana Zelizer contains similarities with that of Schutz. Zelizer (2004) has developed the notion of 'circuits of commerce', which are best thought of as distinct provinces of meaning that structure the market and provide guidance for the behavior of individuals. Even though 'Zelizer circuits' (Collins 2004) do not explicitly refer back to a phenomenological root, the two central arguments of her work-the existence of multiple currencies that are distinct and not perfectly exchangeable, and the idea that different markets give rise to different subjective experiences-provide a way to trace back Schutzian building blocks. Zelizer (2005) details how the valuation of homemaking labor is subject to a plethora of negotiations that intertwine love and money, and how the logic of both structures the way rewards and incentives are perceived. Her earlier empirical work details the way in which life and death, or the loss of a close relative, came to be valued differently through the rise of the markets for life-insurance (Zelizer 1978).

In related work, Olav Velthuis (2005) describes the symbolic meaning of prices and the intricate way in which artistic and economic ways of valuing a new work of art are negotiated in the front and back room of contemporary art galleries. He demonstrates that gallerists do not simply face incentives to increase or lower prices, but instead, that price symbolizes possible paths of action in ways understood to market insiders and negotiated 
between buyers, dealers, and artists (Velthuis 2004). These works rely on actors' understandings, focus on the process of coordination of plans, the associated language, and the resulting structures of meaning.

One might be tempted to argue that this is only to be expected in these somewhat more marginal markets. But recent explorations of the world of finance show that the same is true of central capitalist markets. Knorr-Cetina and Bruegger (2002) contend that global financial markets work on the basis of a 'temporal coordination'. This notion, inspired by Schutz's work, is used to discuss the intersubjectivity that agents in global markets develop during the process of doing their work, especially currency trading in global investment banks. Based on empirical findings, the authors argue that if markets coordinate, it is because there is spatial-temporal synchronicity that allows for intersubjective relationships between traders. Their research delves into the work of participants who are geographically distant, disengaged from local settings, but bound together by global microstructures. Knorr-Cetina and Bruegger (2002, p. 907) contend that these 'patterns of relatedness and coordination ... are global in scope but microsocial in character'. Also, in the realm of temporal coordination, Abolafia (2001) produces one of the first works that provide an in-depth look at subcultures of Wall-Street, showing how agents negotiate tensions between short- and long-term plan coordination, and how the temptation toward excess spurs market activity.

The issue of interaction in financial markets is widely discussed in economic sociology. Based on ethnographic fieldwork, Smith (2012) shows that narratives mold prices in financial markets since agents work in highly ambiguous environments. Thus, narratives would provide 'meaningful, ordered and unified accounts of how particular events unfold' (Smith 2012, p. 141). Preda (2012) argues that foreign currency traders in uncertain environments, where the price is set in the process of opening offers and receiving counteroffers, adapt their decisions contingently, not depending on previous decisions about which price is optimal. Ethnographic work, such as Zaloom (2006) and Ho (2009), show how financial markets work from the perspective of daily life. These studies all show the rich symbolic nature of markets, where actors attempt to make sense of the world around them and the actions of others. Prices do not act as simple incentives in these markets but are instead created in the process and given meaning in the narratives that become dominant. ${ }^{6}$

The process of 'creation' is shown to be even more central in financial markets that prioritize the notion of performativity. This concept is used to describe the process by which actors adopt models or concepts that were originally conceived (in scientific discourse) to describe their actions. Holmes (2013) studies the way in which actions of central bankers are informed by concepts and models derived from economic theory. And especially in the ethnographic work of Miyazaki (2006), we find an interesting way in which performativity leads to coordination. His argument is that a particular set of (rational) trading strategies are possible in the first place because of a 'faith' in efficient-market assumptions, which entail the notion of an anticipated future, projected and managed to correspond to theoretical constructs. Thus, we have here, in Schutzian terms, an interesting way in which

\footnotetext{
${ }^{6}$ This ongoing sense-making is crucial since, as James Buchanan has argued, the act of choice is not based on '[maximizing] utilities described in independently-existing functions', and therefore 'the potential participants do not know until they enter the process what their own choices will be' (Buchanan 1982, p. 5).
} 
ideal types are enacted by traders who expect other traders to behave like the ideal type. As such, it becomes an important coordinating structure, but only because of mutual understanding and only within a confined domain.

The notion of performativity, as used by these authors, builds on the view that coordination comes about as a result of the familiarity of the actors with the theory that is behind their actions. Morgenstern and Schwödiauer (1976), however, showed that, especially in the cases that involve small numbers of actors, attaining a stable equilibrium may actually get upset when the knowledge of the theory is 'absorbed' by the actors. In that case, some of them might try to trick others into thinking that they are following some other theory. This would, in turn, result in a change in the observations that others are using for their predictions, and, consequently, the predicted equilibrium would break down.

There are two other domains worth highlighting. In the work of Boltanski and Thévenot (2006) six different 'worlds' of justification are delineated. These are distinct and partially overlapping and conflicting provinces of meaning. For example, their notion of justifications found in the inspired world, and how these interact with those given in the market world, provide excellent case studies for how different understandings of the world give rise to differing understandings and to only partially coordinated plans, and how discoordination and conflict arise. Also, they note how particular signals that are interpreted as powerful incentives in one domain (i.e., the critical praise of peers) can be far less powerful in another domain. David Stark (2009) has extended this framework to analyze conflicts within organizations. And, from a somewhat different background, the institutional logics literature has analyzed conflict between different 'logics' operating within organizations, communities or societies (Thornton, Ocasio, and Lounsbury 2012).

Jens Beckert emphasized how goods and other artifacts come to be valued in the modern economy (Beckert and Aspers 2011; see also Karpik 2010; Lamont 2012). This literature examines the question of uncertainty and ambiguity regarding how things get valued, and how the value of goods gets justified, perceived and actively constructed. In more recent work, Beckert (2016) has extended this to how the uncertain future is valued. Drawing on Schutz's work, in which actors convey information and expectations about the future, entrepreneurship comes to play an important role as the quintessential economic practice that transforms uncertainty into potential actions and opportunities. It starts from the perspective of the actor, and the possibility of discoordination stemming from uncertain future projects, and shows the process of coordination in an uncertain world. In Beckert's work, we thus find the first elements of Verstehen as well as that of project formation.

\section{Recent Economics}

While it is perhaps to be expected that Schutzian elements are present in contemporary economic sociology, his work has not been explicitly acknowledged in economics. Nonetheless, we aim to demonstrate in this section that recent economic approaches contain plenty of Schutzian 'building blocks'. And precisely because this is not fully recognized, there is great potential for more engagement between sociology and economics.

New institutional economics has been influenced by game theory, a theory of strategic interaction. This has led to discussions over the nature of institutions in game-theoretic terms. Some have argued that institutions are best understood as constraints on individual 
behavior (e.g., North 1990). This approach still relies on an objective notion of costs and constraints. However, a more interesting approach suggests that institutions are equilibrium outcomes of repeated games (Greif and Kingston 2011). Multiple equilibria are possible, and through coordination, individuals settle on a particular equilibrium that turns into a norm or a rule. These norms are self-enforcing to the extent that individuals have an interest in following the norm given that they expect others to do the same. The seminal example is driving on the right side of the road. A particular institutional arrangement is but one of several possible solutions that can emerge based on the same objective factors. As Thomas Schelling (1960, p. 57) puts it, '[p] eople can often concert their intentions or expectations with others if each knows that the other is trying to do the same'. He describes the mechanism as involving focal points, which he explains are 'clue[s] for coordinating behavior'. He illustrates this with an example of a husband and a wife trying to find each other in the department store. There is no 'right' or dominant strategy, to solve this coordination problem; it critically depends on what they 'expect [each other] to expect to be expected to do' (Schelling 1960, p. 57). From this, they may be able to choose the right place to meet. It is telling that Schelling uses an example of a married couple and not a pair of completely random strangers, since it is crucial for the successful coordination that participants know each other or share some common beliefs that they can both rely on when identifying the appropriate, or salient, focal point (Sugden 1989, 2005; Mehta, Starmer, and Sugden 1994). ${ }^{7}$

The idea that shared beliefs play a role in equilibrium selection is central in the work of Greif $(1994,2006)$. His comparative study of the medieval societies of Genoese merchants and Maghribi traders assumes that cultural beliefs, that is 'ideas and thoughts common to several individuals that govern interaction' (Greif 1994, p. 915), play an important role in shaping economic outcomes by contributing to the path dependence of the emergent institutional arrangements. Greif shows that individualistic and collectivist cultural heritages of the Genoese and Maghribis, respectively, shaped the different expectations that merchants in these societies held with respect to retaliation for the cheating behavior. This, in turn, affected the institutional solutions that developed to deal with these agency problems. Greif's game-theoretic analysis depends on the meaning structures provided by a particular cultural and historical context, since the development of institutions as stable equilibria that guide behavior through the alignment of incentives relies on shared belief systems in the society. ${ }^{8}$ Other economists have extended this approach to study organizations and political institutions (see Greif and Kingston 2011, Sections 5.2-5.3).

Similarly, Aoki evokes the concept of societal rules, which he defines as 'commonly cognized, salient patterns of the ways in which societal games are recursively expected to be played' (Aoki 2001, p. 23). They differ from formal rules in that they are recursively observed. In order to be effective, these observed rules need to be shared. Aoki argues

\footnotetext{
${ }^{7}$ Another famous Schelling example is two people trying to meet in New York City. While experimental results showed that majority of participants indeed succeeded in meeting each other by choosing the information booth at Grand Central Station at 12 o'clock noon, the fact that this, as Schelling points out, 'may reflect the location of the sample in New Haven, Connecticut' (Schelling 1960, p. 55n) suggests precisely the presence of a certain shared knowledge among the sample population.

${ }^{8}$ In situations in which an institution generates behavior, the knowledge and information that are compressed into the institutionalized rules enable and guide individuals, despite their limited perception, knowledge, and computational ability, to act in a manner that leads to behavior and reflects the constraints on admissible beliefs and behavior that the game-theoretic equilibrium analysis captures' (Greif 2006, p. 126).
} 
that while individuals learn and form beliefs by recognizing patterns in their environment, real shared knowledge comes in the form of cultural heritage. He demonstrates this by comparing different institutional solutions to irrigation problems in two villages in Japan and Korea, showing that cultural factors had a key impact on the equilibrium selection.

Bates et al. (1998) describe a unified methodology for combining interpretive work with the rational choice approach. Their programmatic statement comes in the form of what they call analytic narratives. The group of researchers involved in this program characterize themselves as being part of a 'critical trend among a subset of rational choice theorists who have been trying to integrate interpretive and rationalist accounts' (Bates et al. 2000, pp. 697-8). At the core of their approach is a combination of a narrative and historical approach with rational choice theory and game theory, where the case studies and narrative techniques are employed in order to 'understand the actors' preferences, their perceptions, their evaluation of alternatives, the information they possess, the expectations they form, the strategies they adopt, and the constraints that limit their actions' (Bates et al. 2000 , p. 11), which is then used to construct a game-theoretic account. Several Schutzian building blocks can be recognized here: there is a reliance on the method of Verstehen, the central question is how mutual coordination can happen, and, although generally not explicit, there is often a reliance on ideal types in analyzing the actions of different groups.

There is also some empirical work on how entrepreneurs actively seek to change established understandings of particular goods, which builds on the analytical narrative approach. Shared meaning is in these studies not taken as a background against which economic actors make decisions, but rather as a malleable foreground through which actors try to change the possible range of projects which can be (legitimately) undertaken. In his case study of surrogate motherhood, Pavel Kuchař has studied how entrepreneurs played an active role in altering the understanding of contested commodities. His work demonstrates how the illegitimate practice of 'selling babies' was transformed into an accepted market for 'renting wombs' (Kuchař 2016). His analysis shows how what was originally both legally and socially perceived as an illegitimate activity gets transformed into an accepted-or even honorable-practice. He has extended this work to suggest that market exchange, more generally, builds on accepted understandings of particular 'artifacts', which are transformed by entrepreneurs to create new market categories through exemplary goods ${ }^{9}$ (Dekker and Kuchař 2016, 2017).

Even the new institutional approach, building on the work of Douglass North and treating institutions as rules rather than equilibria, recognizes that cultural understandings cannot be ignored. North draws attention to the idea that 'subjective perceptions of the actors are not just culturally derived but are continually being modified by experience that is filtered through the existing (culturally determined) mental constructs' (North 1990, p. 138). He develops this in work with Arthur Denzau on shared mental models that serve as an aid to overcome uncertainty (Denzau and North 1994). Although North makes only limited attempts to explain how such shared mental models emerge, his approach, too, recognizes the importance of the meaning of incentives by emphasizing the role of the diverse intersubjectively shared frameworks of mental models for interpreting the environment. While his subsequent work does not put the questions of meaning at

${ }^{9}$ These exemplary goods have affinities with Weberian ideal types (Dekker 2016, p. 107). 
the center of interest, his recognition of the role of meaning structures has opened the door for many later researchers, as we demonstrate below.

More explicitly Schutzian, and more explicitly concerned with the study of the emergence of shared mental models, is the recent empirical work in the Austrian tradition. Don Lavoie (2011) has argued that economists have wrongfully restricted themselves to price coordination only. His work has sought to explore other types of coordination. He did so through studies of entrepreneurs, which he called the interpretive agents seeking to develop new ways of understanding the world: 'profit opportunities are not so much like road signs to which we assign an automatic meaning as they are like difficult texts in need of a sustained effort of interpretation' (Lavoie 2015, p. 59).

Such understanding led Virgil Storr (2004) to study different entrepreneurial spirits in the Bahamas. He demonstrates that a particular way of understanding entrepreneurship based on the narrative of the pirate is central to the local entrepreneurial spirit, which makes entrepreneurs see a range of opportunities and ways of making a deal that are very different from traditional notions of market entrepreneurship. The pirate, Storr argues, is a kind of ideal-typical entrepreneur, the reliance on which structures later actions. In more recent work he has studied the entrepreneurship of local community leaders in the aftermath of hurricane Katrina (Storr, Haeffele-Balch, and Grube 2015; Storr and Chamlee-Wright 2010). Emily Chamlee-Wright (1997) similarly started out by studying the entrepreneurial culture in a non-standard context, in her case women in Ghana. Her methodology is based on interviews through which she seeks to explore how the actor's perspectives of opportunities are structured by cultural frames. Culture within these works serves as an interpretive lens through which entrepreneurs perceive the world, and through which coordination in markets is made possible. Furthermore, this work emphasizes that shared cultural frames are even more important in the absence of formal institutional structures, and thus it acts as a complement to some of the work in institutional economics discussed above.

A slightly different approach that relies on the use of ideal types is the work of Roger Koppl (2002) on 'big players'. He explicitly develops Schutz's notion of the levels of anonymity on which social actors rely. He argues that in most markets there will be a relatively high degree of anonymity, and thus the actors can form their expectations based on anonymous ideal types. But in markets with a few big firms (oligopoly), or in markets with one big player such as the central bank, economic actors will develop quite sophisticated interpretations of the likely actions of some other actors, since in forming their expectations small actors will have to take into account the power of the big players to make idiosyncratic moves. For Koppl, the ability and willingness of certain, usually big, economic agents to act discretionary as opposed to following a set of rules results in a distortion of expectations among other agents, and in attempts by the latter to align as close as possible to the actions of the big player. He applies this to financial markets and the elaborate attempts to predict the likely course of action, typically regarding the interest rate, of the central bank.

Koppl also raises the possibility that expectations need not be identical to be coordinated. In such a case, coordination may be sustained even as the mental models are not shared but differ. Such 'false mental models' may thus nevertheless lead to a situation where 'the players are oriented to different visions of the future and yet neither party is ever disappointed' (Koppl 2002, p. 91). While such coordination remains a possibility, the reality of the social world nevertheless is predominately based on the shared models 
due to a mix of invariant human biological traits and 'universal' social principles emerging from human interaction.

The insight emerging from these different economic studies is that coordination in markets depends on shared frames of reference as much as on prices. There are no simple incentives out there; actions arise from shared understandings of what is likely to happen and what is expected of others. In the case of contested commodities, the buying and selling of a certain artifact is regarded improper and hence the 'incentive' to do so ignored. In other instances, entrepreneurs discover new opportunities and create 'incentives' for others to follow. In yet others, there is no single signal guiding the way, since the success of a projected action depends on what others will do, and hence mutual coordination is crucial. Even more than in sociological studies, economists emphasize ways in which shared understandings emerge and are transformed. In line with Beckert (2016), they demonstrate that the future is not merely uncertain-it is actively shaped through market coordination to overcome that uncertainty. The one building block virtually absent from these studies is that of different provinces of meaning.

\section{The Meaning of Incentives, a Constructive Research Program}

Above we demonstrated how a number of Schutzian themes are present in recent empirical work in both economics and economic sociology. It has been acknowledged for some time now that economics seems to be moving away from theory toward more applied or empirical work (Hamermesh 2013), and this might foster new avenues for exchange with neighboring disciplines. The exchange with psychology in the form of behavioral economics is a famous example of such an exchange. Meaning in this particular exchange is largely ignored in favor of understanding underlying psychological mechanisms. This need not be the case, as two of us have argued elsewhere, since other combinations of psychology and economics are possible (Dekker and Remic 2018) that leave more space for a focus on meaning. But incentives dominate the economic literature. As one of the popular books on the subject has it: 'an incentive is simply a means of urging people to do more of a good thing and less of a bad thing' (Levitt and Dubner 2005, p. 17). What could be simpler?

It is the assumption of the simplicity of incentives that is undercut in the empirical literature we have explored. By showing how shared meaning structures coordinate the actions of individuals it becomes clear that it is the meaning of incentives, and not their inherent or natural force, that gives them power. There is nothing natural about the symbolic value of certain photo-shoots that makes them prestigious and hence so attractive that they do not require a payment, as in the study by Mears (2011). Nor is there anything inherent in lower prices that make them suspicious, yet in particular settings such as primary art markets, lower prices might function as a reason not to buy (Velthuis 2005). Similar effects can be observed in the examples cited by Frey and Jegen (2001) on intrinsic motivation, where the introduction of monetary compensation works as a deterrent rather than an attractor for certain behavior. A classic example is the way in which the amount of blood donated drops after payment for it because the prosocial meaning of the act is undermined. Another example is the way in which parents interpret a fine for picking up their children late from the daycare center. Without this fine more parents were on time, as they considered this their duty; the fine was interpreted as a 
price for being late which removed the duty of being on time (see Gneezy and Rustichini 2000).

This could amount to little more than a note of caution: beware of the simple use of (monetary) incentives. The Schutzian insight is that the problem goes deeper than it appears at first sight. Since particular signals are interpreted in relation to the existing intersubjective meaning structures, the real problem facing the individual is how to interpret a particular signal. This is a cognitive or knowledge problem, not merely a problem of fixing the incentives. Foss and Garzarelli (2007, p. 795) drive that point home in an article critical of the way mainstream economics deals with incentives:

Mainstream conceptions of institutions such as firms and markets ignore the positive cognitive role that such institutions play, that is, their ability to coordinate different expectations through time is downplayed, and all attention is focused on how these institutions may align incentives.

In other words, by thinking in terms of incentives we take for granted that these can be meaningfully interpreted by actors in the first place, and we ignore the institutional structure (in economic language), or the shared meaning (in Schutzian language), that makes such interpretation possible in the first place. Our first conclusion is that understanding the meaning structure within which incentives operate is essential to understanding what effects they will have.

In the previous sections we have seen that in many empirical studies a methodology of ideal types is implicitly or explicitly developed in order to make sense of the actions of others. This was explicitly done in Koppl's (2002) study of big players in financial markets, the interpretation of whose actions involve great cognitive exertion by many of the other players in the market, all the while they are being content to accept a fairly simple representation of the other (small) players in the markets. It was explicit in work on the performativity of rational-actor models in financial markets by Miyazaki. In the economic histories we mentioned we also saw that particular groups (as well as individuals) are modeled (often in a game-theoretic setting) as being of a certain type with a stylized motive. This allows economic historians to analyze the various coalitions seeking to arrive at a beneficial outcome. Their effort is interpretive in the sense that they try to model the decision situation for the historical actors, but they utilize an implicit methodology of ideal types to analyze large-scale historical developments.

Although not all studies do this explicitly, it does open up the possibility for more sophisticated thinking about incentives and institutional change. Many economic histories show how conflict situations are reinterpreted so that cooperative coalitions can be built, which support new institutions that shape the future expected behavior of the actors (obviously this can also happen the other way around so that others are no longer regarded as potential coalition partners). On a smaller scale, Elinor Ostrom (1990) studied this issue for communities seeking to overcome common-pool resource problems. This underlines the fact that thinking about ideal types, and the mutual understanding of actors, shapes the (potential) outcomes of a situation. Non-cooperative situations can turn into cooperative ones. This point is emphasized within the economic sociology literature, which often demonstrates the intricate ways that competition and cooperation go together in social interactions, as well as the importance of certain social logics with clearly defined roles (Thornton, Ocasio, and Lounsbury 2012; Steiner 2010). This leads to our second 
conclusion: incentives are inextricably linked to the roles of different actors, which can be made intelligible through the methodology of ideal types.

The third building block is that of the coordination process that happens through project formation. Economics has a long tradition of studying entrepreneurship in a variety of settings and, as we demonstrated above, increasingly in non-market settings. Within the Schutzian framework, every action based on a project or plan has entrepreneurial aspects. But, when shared meaning structures are absent or disrupted, empirical studies of entrepreneurial behavior and the resulting coordination or conflicts can be highly illuminating of how individuals understand the incentives and opportunities in the world around them. Recent studies in the sociology of finance have highlighted how institutions help shape expectations about highly uncertain futures, and Beckert (2016) is a deeply Schutzian project, as demonstrated above. Increasingly, economic sociologists have studied how uncertainty is reduced through a variety of judgment devices (Karpik 2010), and other types of coordination which act as guideposts in uncertain terrain.

Economists typically focus on prices as the primary institution providing guidance for future economic action, but we have highlighted how they increasingly are paying attention to other institutions that help structure expectations about the future. Again, this work is in part stimulated by game-theory, where prices are not as central as elsewhere in economics. Moreover, Storr and Chamlee-Wright's (2010) work on post-disaster recovery shows that entrepreneurship can be social and coordination can take place through announced actions by leaders. That work also shows how particular individuals are important in shaping the future, a point that also comes out clearly in Koppl's (2002) work on Big Players, such as central banks. This leads us to our third conclusion, which is that through the study of entrepreneurship we can grasp how different actors understand and imagine possible futures of the world differently. In the open-ended situations that entrepreneurs face, we can study how they interpret the limited cues and signals about the future and base their projects on these. Limited coordination or discoordination are likely to occur. Empirical studies are crucial here since the way uncertainty is reduced, or judgments are formed, differs in different markets.

The fourth building block we identified in the second section-multiple provinces of meaning-is reflected in the empirical and conceptual literature in economic sociology. It underlies the theory of the circuits of commerce, work on the different worlds of justification by Boltanski and Thévenot (2006), and the literature on institutional logics. It is also reflected in empirical work in economic sociology, whose purpose is often to identify the particular province of meaning that structures a particular market. Within economics, however, it is harder to find explicit instances where authors draw on the idea of different 'provinces of meaning'. The exception is a paper on surrogate motherhood by Kuchař (2016), which explicitly deals with the different logics attached to the idea of motherhood and to the exchange on markets. While nobody is in favor of selling and buying babies, reconciling these different logics occurs when the idea emerges that not the baby is bought and the mother receives money for it in exchange, but instead the womb is rented out, for which the surrogate mother can be compensated.

Empirical work can be done in economics on related issues such as 'contested commodities' (Radin 1996). These are goods that, traditionally, have not been exchanged on markets, or whose commodity status is contested. For these goods it is clear that competing understandings of the good are involved, linked to different provinces of meanings and 
institutional structures. This is more relevant because markets are being designed for some of these contested commodities, such as kidneys and school enrollment. These mechanisms, which often mimic market mechanisms (although only partially), are used for the distribution of particular scarce goods for which normal market exchange is not acceptable. There is awareness that this project runs into what Alvin Roth (2007) has called 'moral repugnance', but there is a poor understanding that this moral repugnance is not a natural repugnance, but instead a competing set of meanings associated with particular artifacts. Just like monetary incentives might upset existing motivations, so here market-like distribution will upset existing meanings and associations. If we wish to make these markets function well, or to criticize them intelligently, an understanding of the multiple provinces of meaning is necessary. The fourth conclusion we draw from this is that markets are typically their own province of meaning which is (potentially) in conflict with other social processes containing rival and complementary meanings. To understand why markets and (monetary) incentives are sometimes not accepted, we need to understand these interrelations.

\section{Conclusion}

This paper demonstrates the convergence of recent empirical approaches in economics and economic sociology along Schutzian lines. It identifies four Schutzian building blocks: Verstehen, methodology of ideal types, coordination of projected plans, and provinces of meanings. Except for the fourth, they all appear in recent economic work, especially in new institutional and Austrian economics; all appear in recent work in economic sociology.

This does not mean that there is a coherent or unified new approach; however, there is a promising avenue for future research at the intersection of economic sociology and these branches of economics. We have shown that this can be a constructive research program that can contribute to a central issue in economics-how incentives work. The approaches discussed illuminate: (i) why certain incentives are perceived as powerful reasons for action, while others are mostly ignored; (ii) why incentives are typically tied to certain social roles that can be identified through ideal-type analysis; (iii) why situations of high uncertainty are useful in studying how actors make sense of the world and how an uncertain future is understood by actors; and (iv) why monetary rewards and market exchange sometime provide the wrong type of incentive.

To pursue this line of research, it is valuable to recognize the important contribution of Schutz. Elements of his work can be recognized within recent empirical work in both disciplines, and his work can serve as a theoretical and methodological foundation for these new approaches. His interpretative social science, focusing on mutual coordination by many individuals operating in divergent provinces of meaning, is not only appropriate for the modern plural world but can also help us analyze small-scale (micro) interaction and large-scale (macro) interaction. It also combines elements of individual choice and subjective valuation common to economics, with notions of norms, shared (sub)cultures, and different domains in society, that are found in sociology.

Incentives indeed matter, but they do not matter in and of themselves. We have to pay attention to the general dynamics of intersubjective meaning that enable economic actors to interpret signals. The way a particular signal is interpreted, so that it comes to be 
understood as an incentive or a disincentive for action, is crucial for understanding social interaction. Within this research program, incentives are not objective facts of the social world; they are thing understood by actors.

\section{Acknowledgements}

The authors would like to thank Pavel Kuchař and two anonymous referees for their helpful comments and suggestions.

\section{Disclosure statement}

No potential conflict of interest was reported by the authors.

\section{References}

Abolafia, M. 2001. Making Markets: Opportunism and Restraint on Wall Street. Cambridge, MA: Harvard University Press.

Aoki, M. 2001. Toward a Comparative Institutional Analysis. Cambridge: MIT Press.

Augier, M. 1999. 'Some Notes on Alfred Schutz and the Austrian School of Economics.' Review of Austrian Economics 11: 145-162.

Bates, R., A. Greif, M. Levi, and J. L. Rosenthal. 1998. Analytic Narratives. Princeton, NJ: Princeton University Press.

Bates, R. H., A. Greif, M. Levi, J. L. Rosenthal, and B. R. Weingast. 2000. 'The Analytic Narrative Project.' American Political Science Review 94 (3): 696-702.

Becker, J. 2016. Imagined Futures. Cambridge, MA: Harvard University Press.

Beckert, J., and P. Aspers. 2011. The Worth of Goods: Valuation and Pricing in the Economy. Oxford: Oxford University Press.

Boltanski, L., and L. Thévenot. 2006. On Justification: Economies of Worth. Princeton, NJ: Princeton University Press.

Buchanan, J. 1982. 'Order Defined in the Process of Its Emergence.' Literature of Liberty 5: 5.

Chamlee-Wright, E. 1997. The Cultural Foundations of Economic Development: Urban Female Entrepreneurship in Ghana. London: Routledge.

Collins, R. 2004. Interaction Ritual Chains. Princeton, NJ: Princeton University Press.

Dekker, E. 2016. 'Exemplary Goods : Exemplars as Judgment Devices.' Valuation Studies 4 (2): 103-124.

Dekker, E., and P. Kuchař. 2016. 'Exemplary Goods: The Product as Economic Variable.' Schmollers Jahrbuch 136 (3): 237-255.

Dekker, E., and P. Kuchař. 2017. 'Emergent Orders of Worth: Must We Agree on More Than a Price?' Cosmos and Taxis 4 (1): 23-34.

Dekker, E., and B. Remic. 2018. 'Two Types of Ecological Rationality: Or How to Best Combine Psychology and Economics.' Journal of Economic Methodology 26 (4). https://doi-org.eur.idm. oclc.org/10.1080/1350178X.2018.1560486

Denzau, A., and D. North. 1994. 'Shared Mental Models: Ideologies and Institutions.' Kyklos 47 (1): 3-31.

Foss, N. J., and G. Garzarelli. 2007. 'Institutions as Knowledge Capital: Ludwig M. Lachmann's Interpretative Institutionalism.' Cambridge Journal of Economics 31: 789-804.

Frey, B., and R. Jegen. 2001. 'Motivation Crowding Theory.' Journal of Economic Surveys 15 (5): 589-611.

Gneezy, U., and A. Rustichini. 2000. 'A Fine Is a Price.' Journal of Legal Studies 29: 1-17.

Greif, A. 1994. 'Cultural Beliefs and the Organization of Society: A Historical and Theoretical Reflection on Collectivist and Individualist Societies.' Journal of Political Economy 102 (5): 912-950. 
Greif, A. 2006. Institutions and the Path to the Modern Economy. Cambridge: Cambridge University Press.

Greif, A., and C. Kingston. 2011. 'Institutions: Rules or Equilibria?' In Political Economy of Institutions, Democracy and Voting, edited by N. Schofield and G. Caballero. New York: Springer.

Hamermesh, D. 2013. 'Six Decades of Top Economics Publishing: Who and How?' Journal of Economic Literature 51 (1): 162-172.

Ho, K. 2009. Liquidated: An Ethnography of Wall Street. Durham, NC: Duke University Press.

Holmes, D. 2013. Economy of Words: Communicative Imperatives in Central Banks. Chicago, IL: University of Chicago Press.

James, W. 1890. The Principles of Psychology, Vol. 2. New York: Henry Holt and Company.

Karpik, L. 2010. Valuing the Unique: The Economics of Singularities. Princeton, NJ: Princeton University Press.

Knorr-Cetina, K., and U. Bruegger. 2002. 'Global Microstructures: The Virtual Societies of Financial Markets.' American Journal of Sociology 107 (4): 905-950.

Koppl, R. 2002. Big Players and the Economic Theory of Expectations. New York: Palgrave Macmillan.

Kuchař, P. 2016. 'Entrepreneurship and Institutional Change: The Case of Surrogate Motherhood.' Journal of Evolutionary Economics 26: 349-379.

Lachmann, L. 1971. The Legacy of Max Weber. Berkeley, CA: Glendessary Press.

Lamont, M. 2012. 'Toward a Comparative Sociology of Valuation and Evaluation.' Annual Review of Sociology 38 (21): 201-221.

Lavoie, D. 2011. 'The Interpretive Dimension of Economics.' Review of Austrian Economics 24: 91128.

Lavoie, D. 2015. 'The Discovery and Interpretation of Profit Opportunities: Culture and the Kirznerian Entrepreneur.' In Culture and Economic Action, edited by L. E. Grube and V.H. Storr. Cheltenham: Edward Elgar.

Levitt, S., and S. Dubner. 2005. Freakonomics: A Rogue Economist Explores the Hidden Side of Everything. New York: HarperCollins.

Machlup, F. 1936. 'Why Bother with Methodology?' Economica 3 (9): 39-45.

Mears, A. 2011. 'Pricing Looks: Circuits of Value in Fashion Modeling Markets.' In The Worth of Goods: Valuation and Pricing in the Economy, edited by J. Beckert and P. Aspers. Oxford: Oxford University Press.

Mehta, J., C. Starmer, and R. Sugden. 1994. 'Focal Points in Pure Coordination Games: An Experimental Investigation.' Theory and Decision 36: 163-185.

Miyazaki, H. 2006. 'Economy of Dreams: Hope in Global Capitalism and Its Critiques.' Cultural Anthropology 21 (2): 147-172.

Morgenstern, O., and G. Schwödiauer. 1976. 'Competition and Collusion in Bilateral Markets.' Zeitschrift für Nationalökonomie 36: 217-245.

North, D. 1990. Institutions, Institutional Change and Economic Performance. Cambridge, MA: Cambridge University Press.

Ostrom, E. 1990. Governing the Commons. Cambridge: Cambridge University Press.

Preda, A. 2012. 'Interactions and Decisions in Trading.' In The Sociology of Finance, edited by K. Knorr-Cetina and A. Preda. Oxford: Oxford University Press.

Prendergast, C. 1986. 'Alfred Schutz and the Austrian School of Economics.' American Journal of Sociology 92 (1): 1-26.

Radin, M. 1996. Contested Commodities. Cambridge, MA: Harvard University Press.

Roth, A. E. 2007. 'Repugnance as a Constraint on Markets.' Journal of Economic Perspectives 21 (3): 37-58.

Schelling, T. C. 1960. The Strategy of Conflict. Cambridge, MA: Harvard University Press.

Schutz, A. 1962. Collected Papers I: The Problem of Social Reality. The Hague: Martinus Nijhoff.

Schutz, A. 1967. The Phenomenology of the Social World. Evanston, IL: Northwestern University Press. 
Smith, C. 2012. 'Auctions and Finance'. In The Sociology of Finance, edited by K. Knorr-Cetina and A. Preda. Oxford: Oxford University Press.

Stark, D. 2009. The Sense of Dissonance: Accounts of Worth in Economic Life. Princeton, NJ: Princeton University Press.

Steiner, P. 2010. 'Gift-Giving or Market? Economists and the Performation of Organ Commerce.' Journal of Cultural Economy 3 (2): 243-259.

Storr, V. 2004. Enterprising Slaves \& Master Pirates. New York: Peter Lang.

Storr, V., and E. Chamlee-Wright. 2010. The Political Economy of Hurricane Katrina and Community Rebound. Cheltenham: Edward Elgar.

Storr, V., S. Haeffele-Balch, and L. Grube. 2015. Community Revival in the Wake of Disaster: Lessons in Local Entrepreneurship. New York: Palgrave Macmillan.

Sugden, R. 1989. 'Spontaneous Order.' Journal of Economic Perspectives 3 (4): 85-97.

Sugden, R. 2005. The Economics of Rights, Co-Operation and Welfare. London: Palgrave MacMillan. Swedberg, R. 2003. Principles of Economic Sociology. Princeton, NJ: Princeton University Press.

Thévenot, L. 2001. 'Pragmatic Regimes Governing the Engagement with the World.' In The Practice Turn in Contemporary Theory, edited by T. Schatzki, K. Knorr-Cetina and E. von Savigny. New York: Routledge.

Thornton, P., W. Ocasio, and M. Lounsbury. 2012. The Institutional Logics Perspective: A New Approach to Culture, Structure, and Process. Oxford: Oxford University Press.

Velthuis, O. 2004. 'An Interpretive Approach to Meanings of Prices.' Review of Austrian Economics 17 (4): 371-386.

Velthuis, O. 2005. Talking Prices: Symbolic Meanings of Prices on the Market for Contemporary Art. Princeton, NJ: Princeton University Press.

Wagner, H. 1983. Alfred Schutz: An Intellectual Biography. Chicago, IL: University of Chicago Press.

Zaloom, C. 2006. Out of the Pits: Traders and Technology from Chicago to London. Chicago, IL: University of Chicago Press.

Zelizer, V. 1978. 'Human Values and the Market: The Case of Life Insurance and Death in 19thCentury America.' American Journal of Sociology 84 (3): 591-610.

Zelizer, V. 2004. 'Circuits of Commerce.' In Self, Social Structure, and Beliefs, edited by J. C. Alexander, G. T. Marx and C. L. Williams. Berkeley: University of California Press.

Zelizer, V. 2005. The Purchase of Intimacy. Princeton, NJ: Princeton University Press. 